\title{
Ethical considerations in educational research involving children: Implications for educational researchers in South Africa
}

\begin{abstract}
Adopting a social justice theoretical framework, the author proposes that the involvement of children in educational research is paramount. However, such involvement often exposes children to exploitation and a violation of their rights. As such, it is essential that all research involving children should be ethically sound. Hence, the purpose of this study was to explore ethical considerations in educational research involving children, especially in South Africa, which was historically known for the marginalization of and discrimination against children. This generic qualitative study included a sample of eight experts with extensive knowledge of the ethical concerns surrounding children's participation in research activities. Data was collected through individual interviews, a questionnaire, and the analysis of documents and instruments pertaining to the ethical-legal protection of children's involvement in research activities in South Africa. The findings identify several ethical principles that should be considered within a South African perspective and which have specific implications for educational researchers.
\end{abstract}

Keywords: Children's rights, educational research, ethics, social justice, vulnerable children, United Nations Convention on the Rights of the Child (UNCRC).

Jace Pillay, University of Johannesburg. Email: jacep@uj.ac.za.

South African Journal of Childhood Education | 2014 4(2): 194-212 | ISSN: 2223-7674 |๔ UJ

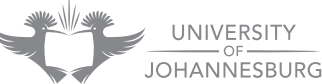




\section{Introduction}

This article notes the importance of educational research in improving the lives of children, but strongly urges that the rights of children be protected throughout the research process. The author articulates the need for educational research, linking it directly with children's rights and sound ethical principles to be adhered to when research is conducted with children as participants.

\section{The need for educational research}

The importance of children in society cannot and should not be undervalued (Smith 2002; Pufall \& Unsworth 2004; Stainton Rogers 2004; Shriberg, Wynne, Briggs, Bartucci \& Lombardo 2011). Hence, research concerning all facets of children's lives is essential, as categorically stated by the Dublin Department of Children and Youth Affairs (2012:V): "We need to understand our children - their lives, their circumstances, their needs and the services and supports required to meet their needs."

The scope of this paper is, however, limited to educational research. The author supports the British Educational Research Association's (BERA 2011:1) position that there will always be a need for educational researchers "to extend knowledge and understanding in all areas of educational activity and from all perspectives, including learners, educators, policymakers and the public". However, the author also strongly argues that, irrespective of the educational research focus, the protection of children's rights must be ensured.

\section{Children's rights}

The United Nations Convention on the Rights of the Child (UNCRC) defines children's rights as follows:

"[...] a set of universal entitlements for every child and young person below the age of 18 . These entitlements apply to every child of every background and encompass what they need to survive and have opportunities to lead stable, rewarding lives."

(Save the Children 2006:4)

Aligned to this definition, the UNCRC identifies four categories of children's rights: the right to survive, the right to be safe, the right to belong, and the right to develop (ibid). All these categories are important in educational research as well (Franklin 2001; Mangold 2002; Covell, Howe \& McNeil 2010), however, in many instances, one notes a conspicuous failure by educational researchers to afford equal prominence to each one. From the proliferation of literature it becomes obvious that research and publications focus rather more on child development than the other three categories. It would appear that what little is done with regard to child survival, safety and belonging falls within the disciplines of psychology and sociology (Hodgkin \& Newell 2007). More importantly, one may argue that there is a dearth of research and literature on the cultural experiences of South African children with regard to all four categories identified. The author unequivocally states that educational research should give equal prominence to each of the four categories, 
taking cognisance of the role that culture plays in shaping children's development, which will inevitably have an impact on educational practices in early childhood education (Freeman 2000; Dawes \& Biersteker 2011). Educational research should move beyond child development to a focus on the developing child. To the author, such a focus warrants a holistic developmental view of the child which takes into consideration the child's need to survive, be safe and belong (Verhellen 1993, 1994; Detrick 1999; Covell \& Howe 1999, 2001a; Howe \& Covell 2007; Covell, McNeil \& Howe 2009, Pillay 2014a).

The UNCRC promotes four core principles, namely non-discrimination, the best interests of the child, the right to life, survival and development, and child participation in decisions made about children (Ludbrook 2000; Smith 2000, 2002; Child Rights Information Network 2008). One may argue that these principles are fundamental and should be the central focus of all research involving children - for example, no child should be discriminated against while participating in research and every effort should be made to ensure that the research is intended to promote the best interests of children. Similarly, all educational research should be directed at the holistic development of children (DeCoene \& De Cock 1996; Covell \& Howe 1999, 2001b; Covell, Howe \& McNeil 2008, 2010; HRiE 2009). Another fundamental aspect of educational research is that it should inform decisions aimed at positively impacting the lives of children. It is essential that children participate in such decisions (Viviers \& Lombard 2013). However, this is often difficult to do in sub-Saharan Africa, due to undemocratic governments that often incite the violation of human rights through civil wars and armed conflict (Machel 2000; Mawson 2004; Kasirye 2007; Sewpaul \& Matthias 2013); a lack of political and financial support for promoting children's rights; inadequate resources and poverty; and societal inequalities and deleterious cultural practices (Bradley \& Whitesede-Mansell 1997; Hernlund 2001; Gose 2002; Buckner, Mezzacappa \& Beardslee 2003; Heyns \& Stefiszyn 2006; Chirwa 2008; Cimpric 2010). These conditions warrant research aimed at improving the lives of children; however, if not conducted in an ethical manner, such research may well contribute to further exploitation of children.

\section{Ethical considerations}

In relating ethics to research conducted with children, most definitions either explicitly or implicitly emphasise the importance of values, moral principles and obligations, and the protection of children from all harm and danger throughout the research process (Sieber 1993; Morrow \& Richards 1996). In an intensive international study, Schenk and Williamson (2005) identified five cross-cutting themes that highlight principles and safeguards that should be considered to ensure that the entire research process is ethically sound. One would argue that these themes are highly relevant within the context of educational research. The first theme emphasizes adherence to basic ethical principles. The authors argue that there is a "difference in power between the participant and investigator" (ibid:3) in the research context, which could result in the exploitation of children. In order to prevent this from happening, researchers must uphold three core principles, namely respect for persons, beneficence, and justice. 
Investigators show appropriate respect for persons when they seek their informed consent to participate in research without placing any pressure on them to do so. If child participants are under the legal age of consent, then the permission of parents or legal guardians is required. The principle of beneficence compels researchers to protect child participants from any harm and at the same ensure the possibility of maximizing benefits to them, and the justice principle dictates that the benefits and burdens of the research activity should be equally distributed (ibid).

The second theme focuses on children's participation in terms of two distinct roles, that is, as participants and respondents. Schenk and Williamson (2005) argue that participation should be maximised, but that research on sensitive topics should be reduced. The third theme endorses national and international legal and professional regulations that promote ethically acceptable research - for example, in South Africa there are professional bodies with set rules which call for ethical supervision of work and research involving children (NHREC 2011).

The fourth theme poignantly underlines the absolute necessity of taking cultural and gender considerations into account throughout the research process (Schenk \& Williamson 2005). Researchers must take cognisance of cultural norms, age and gender, which are critical aspects of child development. The final theme identified by Schenk and Williamson relates to especially vulnerable children, such as orphans, refugees and children without guardians (ibid). It is often difficult to provide follow-up support for these children or to monitor and evaluate services provided to them.

It is clear from the above that strict ethical principles should apply in research involving children. The following section will provide a theoretical understanding of ethics in such research within the context of the present study.

\section{Theoretical perspectives of the study}

This study on ethical research involving children is positioned within a social justice theoretical framework. The author strongly postulates that all educational research involving children should actively promote social justice in the lives of children (Shriberg et al 2011). Upholding the human rights and dignity of all children is a major tenet of social justice theory (Pillay 2014b). This is a salient concern in the South African context, where the apartheid system resulted in the gross violation of children's rights. Furthermore, the lives of many black children are characterised by poverty, poor access to education and health services, crime, and the scourge of HIV/AIDS, to name but a few of the challenges that render them powerless and vulnerable to all sorts of exploitation. A social justice framework compels researchers to treat children with respect and dignity and to ensure that they are provided fair and equal opportunities to develop and function optimally in society, irrespective of their race, gender, class, creed, ethnicity and/or (dis)ability (Pillay 2014a). As such, the author argues that any research that focuses on children's rights and ethics should adopt a social justice theoretical framework. 
This framework requires a paradigm shift among educational researchers in terms of how they conceptualise childhood development, that is, a transition from a needs-based view of children to a rights-based one (Benedetto \& Olisky 2001; Bartolo 2010). A rights-based view challenges the belief that adults are experts on matters pertaining to children and that there is therefore no need to consult children when taking decisions about them (Smith 2002; Stainton Rogers 2004). In contrast, a rights-based view promotes the idea that children should be involved in decisions about matters that concern them. Taking their age and development into consideration, what they have to say matters and must be included in all deliberations centred on them. This view certainly has implications for educational research. It means that children should be actively involved in all studies relating to them, thus affording them the opportunity to express their personal views and relate their experiences at different developmental stages (Pufall \& Unsworth 2004). However, involving children in research is not devoid of problems, especially if child participants are vulnerable to exploitation, hence the reason for this study.

\section{Research methodology}

\section{Research design}

A qualitative research design was used with a view to gaining an in-depth understanding of the ethical issues surrounding research conducted with children within an African context (Krefting 1991; Bless \& Higson-Smith 1995; Merriam 1998, 2002). The descriptive, exploratory and contextual nature of qualitative research makes it appropriate for such a study (Henning, Van Rensburg \& Smit 2004), as it creates an opportunity for the researcher to explore and describe ethical issues that all researchers should be mindful of when they conduct studies with children within the educational context.

\section{Sampling}

Purposive sampling was used in order to select participants who are actively involved in research focused on promoting the welfare of children within the African context. The following selection criteria applied:

1. The participants must be experts and/or professionals, having conducted research involving children for a minimum of 5 years;

2. They must belong or have some affiliation to organisations that promote the welfare of children through research activities; and

3. They must be knowledgeable about policies and instruments pertaining to ethical issues surrounding research conducted with children.

Participants who met these criteria were selected for this study. The final sample comprised a total of eight participants. 


\section{Data collection}

Data was collected through document analysis and individual interviews, or the administration of a questionnaire if participants were unavailable for an interview or lived too far away (that is, outside of Gauteng Province, South Africa). The participants included researchers/academics (Participants 3, 4 and 5); a legal expert (Participant 2); directors of child centres (Participants 1, 7 and 8); and a policy analyst (Participant 6).

\section{Trustworthiness}

The study methodology was in line with Lincoln and Guba's (1985) measures to ensure trustworthiness, with credibility being established through the author's experience and expertise as an educational psychologist and academic actively involved in research directed at improving the lives of children within their educational, social and psychological contexts. The collected data was authenticated by means of follow-up sessions with the participants, while confirmability was ensured by quoting the actual words spoken by participants.

\section{Ethical measures}

In line with the subject of this paper, stringent ethical measures were taken throughout the research process. The Ethics Committee of the Faculty of Education at the researcher's home institution granted ethical clearance for the conduct of the study. All participants were informed from the onset of the research that their involvement was voluntary and that they could withdraw at any point, without penalty (Denzin \& Lincoln 2005). To maintain confidentiality, no participant is mentioned by name in the study.

\section{Data analysis}

Data analysis commenced with a systematic analysis and literature review of instruments, policies and documents pertaining to ethical guidelines for the inclusion of children in research activities. Following this analysis, qualitative data was gathered from the participants by means of the data collection methods mentioned earlier. A qualitative content analysis was then conducted on the collected data (Henning et al 2004). More specifically, Merriam's (1998; 2002) content analysis methods were used for this purpose. Firstly, the author carefully studied each interview transcript or questionnaire to identify the ethical considerations highlighted by each participant as requiring special attention when conducting educational research with children. Secondly, words used or thoughts expressed repeatedly by participants were identified and coded, which allowed the researcher to establish general themes and patterns and ultimately identify the final themes noted below.

\section{Discussion of findings}

The following major themes emerged during the data analysis process: 
1. Child participation in research activities;

2. The need for research ethics committees to safeguard child participants;

3. The requirement that no harm is inflicted on children during the course of the research process;

4. The need for feedback and follow-ups with child participants;

5. Contextual and cultural considerations with regard to research ethics; and

6. Ethical considerations pertaining to especially vulnerable children.

Each of these themes is discussed below. Firstly, participants' actual words are quoted, followed by a discussion to situate the theme in relation to the literature and other documents analysed, as well as the social justice theoretical framework utilised in this study. Finally, the author provides his own interpretation of the findings, wherever appropriate.

\section{Child participation}

The need for child participation in research activities was identified as crucial by all the participants involved in this study. Participant 1 pointed out that "the child is the central person in all research conducted" about them. This was supported by Participant 2, who asserted that "getting children's views on issues that affect them is so important", and Participant 3, who noted that "any research you do interviewing children you are going to get valuable primary data, I mean there is so much that we need to know". These views were succinctly summarised by Participant 5: "[...] interviewing children is often the best way to get the best data about children's problems, for obvious reasons."

While all participants strongly supported the need for child participation in research, some of them were equally concerned about the challenges involved, as captured in the words of Participant 5: "Child participation is a very new area and it's complicated; it has a lot of ethical problems." The main challenge identified is the age and development of child participants. Participant 6 noted contradictions in what the Child Act prescribes and actual practice: "The Child Act says that children must be 12 years and older to participate in research activities, but there are some instances where researchers say that children of whatever age could express their views." Participant 7 strongly believed that young children should not participate in research: "[...] the younger the child, the more vulnerable the child. So I feel strongly that research should not be conducted with young children." However, Participant 6 had a contrasting view: "Never underestimate what a young child can share with you when it comes to things you want to know about them. So I support their involvement in research intended to promote their well-being." Participant 3 was even stronger in her views: "When young children are involved in research it is essential that proper ethical mechanisms are put in place to protect them from all forms of exploitation". Participant 4 also noted that "specific people should be identified to protect the rights of children when they are involved in research". Participant 2 emphasised 
the relevance of the developmental levels of children who participate in research: "Researchers must take the developmental levels of children into consideration when they plan the data collection methods and the kinds of questions they want to ask." This point was also endorsed by Participant 8: "You cannot ask children questions that they are not ready to answer. You must ensure that they are mature enough to understand and respond to what you are trying to do with your investigation."

In addition to the age and development of the child participating in research activities, all the participants emphasized the importance of consent and autonomy. Participant 4 noted: "No one should force children to take part in a study. They should have the right to consent." Participant 6 also pointed out: "According to the law, children older than 12 years must give consent to engage in research. However, a younger child should give assent even if parents or guardians give their consent." Participant 7 felt that even if children consent to participate in research, they should be given autonomy: "Children who agree to take part in a study must be given full autonomy to decide whether to continue or discontinue their participation during any time or stage of the study." Participant 5 supported this view, adding that "there should not be any penalty for non-participation or withdrawal from a study". Participant 3 noted that the issue of consent and autonomy may be particularly important in the case of orphans and vulnerable children: "[...] orphans and vulnerable children are more susceptible to exploitation, so the issues of consent and autonomy have to be more rigorously applied."

Another concern raised about child participation relates to the researchers themselves. Some of the participants felt that some researchers do not necessarily have a solid understanding of child participation, which in itself may raise ethical concerns, as is evident from the words of Participant 4: "How do [researchers] understand an issue such as child participation? How do they make it a part of what their work involves? We come from a society that historically hasn't valued children's viewpoints. How exactly do you understand child participation? I think we have got a long way to go in terms of that." This concern was echoed by Participant 3: "There is no clarity on how child participation is going to, or should be working. Probably the most clarity you will get in participation is in the legal proceedings, which are much more confined, and you have some provisions on participation in schools, which doesn't really work." Participant 8 strongly believed that government should assume responsibility for providing the needed clarity: "There is no clarification on child participation and the government does not seem to have it as a priority. It is the responsibility of government to provide this clarity."

The power differences that exist among children is another area of ethical concern: "We need to be sensitive to the differences that exist amongst children. For example, the experiences of children in rural areas could be quite different from those in urban areas" (Participant 1). This same concern was also articulated by Participant 5: "We must be mindful that children exposed to apartheid, poverty, crime, HIV/AIDS, etc, could be less powerful in expressing themselves due to the legacy they have come from." Participant 4 added gender as a reason for differential power relations: 
"[...] due to a patriarchal legacy, girls may be in a more difficult situation to voice their opinions as a result of sexist practices." Participant 6 believed that it is the responsibility of government to come up with a child participation strategy, so that discriminatory practices may be eradicated and social justice for all children may prevail: "If you do not have a strategy from the government, then you afford some children the opportunity to participate, but you deny others, so it's not fair and leads to a discriminatory effect in the long run."

The need for child participation in educational research has been argued and endorsed by numerous researchers and authors (Danby \& Farrell 2004; Balen, Blyth, Calabretto, Fraser, Horrocks \& Manby 2006; Cocks 2006; Dockett \& Perry 2007). Essentially, all of these researchers and authors maintain that if we want to know more about children, then we have to engage with them and involve them in research activities that concern them. We cannot assume that adults know what is best for children without checking with them. Involving children in this way will inevitably result in their being treated with respect and dignity, as postulated by a social justice framework.

Most of the concerns surrounding child participation that were raised by the participants in this study are not new and have been noted by other authors, for example, age and development (Schenk \& Williamson 2005; Skanfors 2009), consent and autonomy (Allan 2011), and power differences (Coyne 2010, Nsamenang \& Tchombe 2011). However, it is imperative to note that these concerns are critical within an African context, since socio-cultural factors may be different in an African versus a Western context. The concern raised by the participants in this study about researchers' understanding of child participation is crucial in this regard. One may take the principle of consent and autonomy to illustrate this point. While it may be well suited to Western context that endorses individualism, it may be contentious in an African context that embraces communal cultures (Pillay 2014b). This means that in African culture, obtaining 'consent' may not necessarily mean obtaining the consent of the participating children only, but also that of their parents and other significant adults, such as community leaders, tribal chiefs and sangomas. However, Tangwa (2011) argues that while African culture affirms the community over the individual, it still recognizes individuality, as is evident in naming, initiation and burial ceremonies. The author contends that power issues may be of more concern in an African context, since oppression, discrimination, poverty, and gross human rights violations have been and unfortunately continue to be very typical of many African countries. One way of countering power issues is to ensure that all children are included in research activities and not just a selected few - an approach that is in line with a social justice framework.

\section{Research ethics committees to safeguard child participation}

Encouraging child participation in research activities is well and good, but it could be detrimental to children if no mechanisms are put in place to protect their interests. It is clearly evident from this study that ethical issues are given serious consideration when research is conducted, since all the universities represented in this study through the various participants already have well-established research ethics committees. 
Virtually all the participants in this study highlighted the importance of the research ethics committee at their respective universities. For example, participant 1 stated: "I also sat on the university research committee and that's the committee that has to approve projects but also deal with ethics. It is a complex area where one has to be extremely careful." Participant 2 agreed that close ethical monitoring of research involving children is justified: "There are some tricky ethical issues which face researchers, simply because interviewing children is often the best way to get the best data about children's problems. But interviewing vulnerable children can be traumatic or damaging to those children. So institutions of research like our university, and I am sure yours as well, are very careful about that and they have a lot of bureaucracy around getting ethical clearance, which is fundamentally correct." Participant 3 noted that "universities are extremely tight controlled about what you are allowed to do and not do, as they should be." Participant 4 pointed out that it is essential for research committees to know about all research projects right from the onset: "There are certainly ethical committees that you have to go through with your research plan before you engage in anything."

The research ethics committees at some universities are so strict about ethical research that they do not allow novice researchers to engage in research activities with children without the supervision of experienced researchers: "We do not allow inexperienced researchers to conduct research with children without the supervision of properly trained and experienced researchers" (Participant 5). Other universities only allow researchers who have experience of doctoral studies to engage in research activities: "So there are these masters and child care protection students ... when they do their first initial field research assignment, we've actually got a rule which says to them you cannot interview children directly because you are not experienced enough" (Participant 1).

As the above statements by participants show, university research ethics committees act as gatekeepers to ensure that research is conducted ethically. In fact, Lautenbach and Batchelor (2013) point out that research ethics committees play an important role in the entire research process - and one may argue that they are absolutely essential if the interests of children are to be protected within an African context. However, the role of the research ethics committee is not confined to ensuring that research is conducted in an ethical manner; it is also there to safeguard the interests of all involved (the researcher included), knowledge, democratic values, the quality of research, and academic freedom (BERA 2011). According to BERA (ibid:4), there are "diverse educational research philosophies, theories and methodologies", and it is appropriate for research ethics committees to ascertain that the chosen approach is apposite to the research being conducted. More importantly, research ethics committees should ensure that Western theories utilized in local studies are appropriate to the investigations being conducted. Better still, such committees should be instrumental in encouraging the use of African developed theories that fit local contexts. 


\section{No harm to children}

All of the participants stressed the importance of children not being harmed in any way as a result of research being conducted. Firstly, any form of physical harm was vehemently opposed, as reflected in the words of Participant 1: "I think children experience high levels of violence already, particularly girl children. As if this is not enough, we still have to expose them to physical harm during the course of research activities. This must never be tolerated." Participant 8 cautioned that researchers should be vigilant about sexual violence against children: "Sexual violence against children is unbelievable, with vast percentages of children reporting forced sexual intercourse before the age of 15 . Researchers should be sensitive to this and they themselves should not become perpetrators of such acts." Participant 4 also noted the increase in violence against children: "There is a pervasive extent of violence experienced by children, perpetrated upon them mostly by adults, whether it is corporal punishment, whether it's beating or threats to their physical safety on the way to school, at school, or on the way to the toilets."

Any form of psychological harm to children resulting from research activities was also condemned by all the participants in this study. This related mostly to psychological trauma created or evoked during the course of research. Participant 2 stated that the mere act of "interviewing vulnerable children can be traumatic or damaging to those children." Participant 6 warned against retraumatizing of children during the research process: "There should be an awareness of how [researchers] could potentially retraumatize a child. They should do their best to not do this, but if they cannot, then the old adage 'do no harm' should apply." Participant 8 echoed this stance: "Do [research] in a way that will not bring more pain and suffering to a group of people that have already gone through more than most people should have to be able to manage."

One of the main reasons for having ethical guidelines when conducting research is to prevent any harm to children, also referred to as non-maleficence. Researchers have a duty to prevent harm to children, to refrain from engaging in behaviour that may harm others, and to minimize harm when it is unavoidable (Allan 2011). They can cause harm through the use of inappropriate data collection methods, negligence, a lack of competency in using particular research techniques, or by failing to reduce or correct harm. The opposite of non-maleficence is beneficence, or 'doing good', which the author believes should be a prerequisite for educational research. The concept of doing harm is taken very seriously in an African context, as it is a widespread belief that when one does harm to others, one attracts even more harm to oneself and one's community (Tangwa 2011).

\section{Feedback and follow-up}

Another ethical concern raised by some participants is a lack of feedback and follow-up on the part of researchers. Some participants expressed their annoyance at researchers who use children to promote their own selfish interests: "Some researchers write the paper or get the degree or diploma. It then sits in some dusty archive somewhere" 
(Participant 2). Another participant added: "When researchers withdraw, children are generally heartbroken. They are left thinking who that nice lady is and why did she come and talk to me and I have told her all my problems? Is she going to do anything about it?" Participant 7 strongly summed up the concerns about feedback and followup: "There should be no research conducted if it does not have the purpose of doing something about it. It can be damaging, especially for children."

Schenk and Williamson (2005) recommend that research projects should include plans explaining how findings are to be released and what follow-up mechanisms will be implemented. They insist that such plans must include all stakeholders and make provision for the fact that different stakeholders have different information needs. Furthermore, they propose that research results should be shared with the children involved in the studies, as well as their parents or guardians, in a manner that makes sense to them, and that their reactions should also be discussed. The author fully supports these suggestions, which he believes instils a sense of respect for children and thus are in line with a social justice framework in terms of children's rights and research ethics.

\section{Contextual and cultural factors}

Some of the participants placed strong emphasis on contextual and cultural factors in relation to ethical considerations. For example, Participant 1 stated: "I think that issues and challenges on ethics are very multifaceted and very context-specific." Participant 4 agreed, explaining that "there are challenges that are faced by rural children growing up under customary law, where there are practices that are contradictory to children's rights. But in gangland Cape Town there are very different challenges to a very different group of children, but they are equally threatening to children's fulfilment of their rights." As already indicated earlier, in contexts where poverty, crime, substance abuse, and HIV/AIDS are prevalent, the ethical consideration of children are often undermined.

In addition to contextual issues, deleterious cultural practices often contribute to the violation of children's rights and ethics (Pillay 2011; 2014b). Such practices were also noted in this study: "We have a very long way to go towards ridding the continent of patriarchal practices such as early and forced marriages of African girls" (Participant 1). Other cultural practices mentioned were child labour, child soldiers and (unsafe) circumcision (Participants $1 \& 5$ ).

Tangwa (2011) notes that culture and ethics are important aspects of any educational system. He identifies several ethical problems in African countries, such as "fraud, bribery and corruption, nepotism and tribalism, trafficking, and forgery in admission procedures, in evaluation, certification and job recruitment" (ibid:103). However, he also reminds us that there are many positive values in African culture, such as "the extended family/communal spirit, respect/care for the elderly, love of children and parenthood, collective responsibility for the upbringing of the young, modesty, love of harmony, mistrust of dangerous knowledge, etc." (ibid:104). Tangwa argues that these positive values should be affirmed in African culture and not be traded for Western cultural values. In fact, traditional African ethical values should systematically 
be integrated into the pedagogical system. The author believes that this integration should be extended to all research activities and supports Schenk and Williamson (2005) when they say that researchers should consult local advisors to ensure that all research activities are culturally acceptable and gender sensitive; that they should get to know and respect the cultural norms of the communities they are investigating; and that they should even consider the input of local community members in developing research activities. The author notes that contextual and cultural considerations are critical aspects of the social justice theoretical perspective presented in this paper (Pillay 2011).

\section{Especially vulnerable children}

Research conducted with especially vulnerable children was identified as a serious concern in this study, as reflected in the words of Participant 6: "We cannot hide from the fact that in many parts of Africa there is a gross violation of children's rights. So how do we apply ethical principles when children are forced into early marriages, child trafficking, and to be child soldiers?" Participant 1 added: "I know of situations where research was conducted with orphans and street children and once the study was completed nothing tangible were done for the children. It gives me the impression that these children were just used to the benefit of the researchers." Participant 4 described the difficulty she experienced in gaining access to orphans for a study: "It took me more than six months to be able to gain ethical clearance for conducting research with orphans and vulnerable children. I was really upset and demotivated by this, but now, on reflection, I think it was good. It made me realize the importance of ensuring that I adhered to ethical principles throughout the entire research process." Participant 6 shared a similar sentiment: "I think at all costs the safety of vulnerable children must be guarded and their rights must be protected".

The data collected from the participants in this study clearly corroborates the point made by Schenk and Williamson (2005) that especially vulnerable children need more protective mechanisms to ensure that they are not ethically violated during research activities. Examples of especially vulnerable children within an African context are orphans, street children, refugees, children from child-headed families, children living in poverty, famine, and armed conflict. Researchers should, at all times, consider whether obtaining data from especially vulnerable children would place these children at risk and compromise their safety. If there is the slightest doubt about their safety, then the research activities should be immediately aborted. Ensuring the protection of vulnerable children would be an essential aspect of social justice theory, which calls for all children to have an equal chance of being selected for participation in research activities (Pillay 2012). 


\section{Conclusion: Implications for educational researchers in South Africa}

This paper highlighted the importance of educational research and the involvement of children in such research. However, it strongly emphasizes that children's rights should be cautiously protected throughout the entire research process. In order for this to happen, there has to be a rigid application of basic ethical principles by researchers. Bearing this in mind, the author investigated ethical principles which professionals working with children presumed to be essential when conducting research with child participants within a South African context. The findings raise several ethical implications for both educational researchers and the research they conduct. Whilst the study was conducted in South Africa, one may argue that they could easily transcend the boundaries of the African continent.

The first ethical implication relates to child participation, which may be difficult to comprehend and implement in a South African context where children were historically marginalized because of race, gender, culture, class or creed. In fact, through a social justice lens, this is all the more reason why children should participate in research aimed at improving their circumstances, since they know best their experiences of being marginalized. From a practice perspective in relation to social justice theory, educational researchers in South Africa must be cognisant of the fact that child participation in research activities raises concerns around the age and development of children, their ability to give consent and remain autonomous, and the issue of power difference amongst children, which is a stark reality in sub-Saharan Africa. Secondly, research ethics committees must be established to safeguard the interests and rights of children who participate in research. Essentially, such committees would be an appropriate way to put social justice theory into practice. Thirdly, strict mechanisms must be put in place to ensure that children are not harmed in any way through their participation in research. Fourthly, educational researchers should consider it their duty to provide feedback on their findings to children who participate in research activities and do follow-ups with them - not a common practice in most parts of Africa. Fifthly, contextual and cultural factors must be considered when research is conducted with children. Finally, educational researchers must be extremely cautious about the involvement of especially vulnerable children - common in an African context - in research activities. The author concludes by again emphasizing the importance of a social justice perspective in addressing all the implications that have been raised in this study. By virtue of social justice theory endorsing the rights of children, it demands that ethical practices must be considered and institutionalized to protect the interests and welfare of children.

\section{Note}

This work is based on research supported by the South African Research Chairs Initiative of the Department of Science and Technology and National Research Foundation of South Africa. South African Research Chair: Education and Care in Childhood, Faculty of Education: University of Johannesburg, South Africa. Grant no 87300. 


\section{References}

Akello G, Richters A \& Reis R. 2006. Reintegration of former child soldiers in northern Uganda: Coming to terms with children's agency and accountability, Intervention, 4(3):229-243.

Allan A. 2011. Law and ethics in psychology: An international perspective. 2nd Edition. Somerset West, South Africa: Inter-Ed Publishers.

Balen R, Blyth E, Calabretto H, Fraser C, Horrocks, C \& Manby M. 2006. Involving children in health and social research: 'Human becomings' or 'active beings'? Childhood, 13(1):29-48.

Bartolo PA. 2010. Why school psychology for diversity? School Psychology International, 31(6):567-580.

Benedetto AE \& Olisky T. 2001. Biracial youth: The role of the school counsellor in racial identity development. Professional School Counselling, 5(1):66-71.

BERA (British Educational Research Association). 2011. Ethical guidelines for educational research. London: BERA.

Blattman C \& Annan J. 2009. Child combatants in northern Uganda: Reintegration myths and realities. In R Muggah (ed). Security and post-conflict reconstruction: Dealing with fighters in the aftermath of war. New York, NY: Routledge. 103-126.

Bless C \& Higson-Smith C. 1995. Fundamentals of Social Research Methods - An African Perspective. Cape Town: Juta and Co Ltd.

Bradley RH \& Whitesede-Mansell L. 1997. Children in poverty. In: RT Ammerman \& M Hersen (eds). Handbook of Prevention and Treatment with Children and Adolescents - Intervention in the Real World Context. New York, NY: John Wiley \& Sons Inc. 13-58.

Buckner JC, Mezzacappa E \& Beardslee WR. 2003. Characteristics of resilient youths living in poverty: The role of self-regulatory processes. Development and Psychopathology, 15:139-162.

Child Rights Information Network. 2008. United Nations Convention on the Rights of the Child. [Retrieved 14 June 2014] https://en.wikipedia.org/wiki/Convention_on_the_ Rights_of_the_Child.

Chirwa DM. 2008. Combating child poverty: The role of economic, social and cultural rights. In: J Sloth-Nielsen (ed). Children's rights in Africa: A legal perspective. Aldershot: Ashgate Publishing.

Cimpric A. 2010. Children accused of witchcraft: An anthropological study of contemporary practices in Africa. Dakar: UNICEF WCARO.

Cocks AC. 2006. The ethical maze: Finding an inclusive path towards gaining children's agreement to research participation. Childhood, 13(2):247-266.

Covell K \& Howe RB. 1999. The impact of children's rights education: A Canadian study. International Journal of Children's Rights, 7:171-183.

Covell K \& Howe RB. 2001a. Moral education through the 3 Rs: Rights, Respect and Responsibility. Journal of Moral Education, 30:31-42. 
Covell K \& Howe RB. 2001b. The Challenges of Children's Rights for Canada. Waterloo: Wilfrid Laurier University Press.

Covell K, Howe RB \& McNeil JK. 2008. If there's a dead rat, don't leave it: Young children's understanding of their citizenship rights and responsibilities. Cambridge Journal of Education, 38(30):321-339.

Covell K, Howe RB \& McNeil JK. 2010. Implementing children's human rights education in school. Improving Schools, 13(2):117-132.

Covell K, McNeil JK \& Howe RB. 2009. Reducing teacher burnout by increasing student engagement. School Psychology International, 30(3):282-290.

Coyne I. 2010. Accessing children as research participants: Examining the role of gatekeepers. Child: Care, Health and Development, 36(4):452-454.

Danby S \& Farrell A. 2004. Accounting for young children's competence in educational research: New perspectives on research ethics. The Australian Educational Researcher, 31(3):35-50.

Dawes A \& Biersteker L. 2011. Early childhood development. In: AB Nsamenang \& MS Tchombe. (eds). Handbook of African Educational Theories and Practices: A Generative Teacher Education Curriculum. Cameroon: Human Development Resource Centre. 91-108.

DeCoene J \& De Cock R. 1996. The Children's Rights Project in the Primary School 'De Vrijdagmarkt' in Bruges. In: E Verhellen (ed). Monitoring children's rights. The Hague: Martinus Nijhoff. 627-636.

Denzin NK \& Lincoln YS. 2005. The SAGE Handbook of Qualitative Research. Thousand Oaks, CA: Sage Publications.

Detrick S. 1999. A Commentary on the United Nations Convention on the Rights of the Child. The Hague: Martinus Nijhoff.

Dockett S \& Perry B. 2007. Trusting children's accounts in research. Journal of Early Childhood Research, 5(1):47-63.

Dublin Department of Children and Youth Affairs. 2012. Guidance for developing ethical research projects involving children. Dublin: Ministry of Children and Youth Affairs.

Franklin B. 2001. The new handbook of children's rights: Comparative policy and practice. London: Routledge.

Freeman M. 2000. The future of children's rights. Children and Society, 14(4):277-293.

Henning E, Van Rensburg W \& Smit B. 2004. Finding your way in qualitative research. Pretoria: Van Schaik Publishers.

Hernlund Y. 2001. Cutting without ritual and ritual without cutting: Female 'circumcision' and the re-ritualization of initiation in the Gambia. In: B Shell-Duncan \& Y Hernlund (eds). Female 'Circumcision' in Africa. Boulder, CO \& London: Lynne Reiner Publishers.

Heyns C \& Stefiszyn K (eds). 2006. Human rights, peace and justice in Africa: A Reader. Pretoria: Pretoria University Law Press. 
Hodgkin R \& Newell P. 2007. Implementation Handbook of the Convention on the Rights of the Child, 3rd Edition. New York, NY: UNICEF.

Howe RB \& Covell K. 2007. Empowering children: Children's rights education as a pathway to citizenship. Toronto: University of Toronto Press.

HRiE (Human Rights in Education). 2009. Human Rights in Education - 2009 Report. [Retrieved 24 May 2014] http://www.rightsined.org.nz/.

Kasirye R. 2007. Rapid assessment report on trafficking of children into worst form of child labour, including child soldiers in Uganda. Kampala: ILO.

Krefting L. 1991. Rigor in qualitative research: The assessment of trustworthiness. Kingston: Queens University School of Rehabilitation Therapy.

Lautenbach G \& Batchelor J. 2013. Streamlining Processes with Technology: The Research Ethics Committee. In: J Herrington et al (eds). Proceedings of World Conference on Educational Multimedia, Hypermedia and Telecommunications 2013. Chesapeake, VA: AACE. 1-7.

Lincoln YS \& Guba EG. 1985. Naturalistic inquiry. London: Sage Publications

Ludbrook R. 2000. Victims of Tokenism and Hypocrisy: New Zealand's Failure to Implement the United Nations Convention on the Rights of the Child in Advocating for Children. Dunedin: University of Otago Press.

Machel G. 2000. The Impact of Armed Conflict on Children. A Critical Review of Progress Made and Obstacles Encountered in Increasing Protection for War-Affected Children. Report delivered at the International Conference on War-Affected Children, Winnipeg, Canada, September 2000.

Mangold SV. 2002. Transgressing the Border between Protection and Empowerment of Domestic Violence Victims and Older Children: Empowerment as Protection in the Foster Care System. Boston, MA: New England School of Law. [Retrieved 4 March 2008] http://www.nesl.edu/userfiles/file/lawreview/vol36/1/mangold.pdf.

Mawson A. 2004. Children, impunity and justice: Some dilemmas from northern Uganda. In: J Boyden \& J de Berry (eds). Children and Youth on the Front Line: Ethnography, Armed Conflict and Displacement. Oxford \& New York, NY: Berghahn Books. 131-44.

Merriam SB. 1998. Qualitative Research and Case Study Applications in Education. San Francisco, CA: Jossey-Bass Publishers.

Merriam SB. 2002. Qualitative Research in Practice - Examples for Discussion and Analysis. San Fransisco, CA: Jossey-Bass Publishers.

Morrow V \& Richards M. 1996. The ethics of social research with children: An overview. Children \& Society, 10:90-105.

NHREC (National Health Research Ethics Council). 2011. Ethical-legal protection for vulnerable research participants in South Africa: An audit of relevant laws and ethical guidelines. Pretoria: NHREC Press. 
Nsamenang AB \& Tchombe MS (eds). 2011. Handbook of African Educational Theories and Practices: A Generative Teacher Education Curriculum. Cameroon: Human Development Resource Centre.

Pillay J. 2011. Challenges counsellors face while practicing in South African schools: Implications for culturally relevant in-service training. South African Journal of Psychology, 41(3):351-362.

Pillay J. 2012. Experiences of learners from child-headed households in a vulnerable school that makes a difference: Lessons for school psychologists. School Psychology International, 33(1):3-21.

Pillay J. 2014a. Advancement of children's rights in Africa: A social justice framework for school psychologists. School Psychology International, 35(3):225-240.

Pillay J. 2014b. Challenges educational psychologists face working with vulnerable children in Africa. In: T Corcoran (ed). Psychology in Education. Rotterdam: Sense Publishers. 95-111.

Pufall PB \& Unsworth RP. 2004. The imperative and the process of rethinking childhood. In: PB Pufall \& RP Unsworth (eds). Rethinking childhood. New Brunswick: Rutgers University Press. 1-21.

Save the Children. 2006. Children's rights: A teacher's guide. London: Save the Children Fund.

Schenk K \& Williamson J. 2005. Ethical approaches to gathering information from children and adolescents in international settings: Guidelines and resources. Washington, DC: Population Council.

Sewpaul S \& Matthais C. 2013. Editorial. International Social Work, 56(1):3-6.

Shriberg D, Wynne ME, Briggs A, Bartucci G \& Lombardo AC. 2011. School Psychologist: Perspectives on Social Justice. School Psychology Forum, 5:37-53.

Sieber J. 1993. The ethics and politics of sensitive research. In: C Renzetti \& RM Lee (ed). Researching Sensitive Topics. London: Sage. 14-26.

Skanfors L. 2009. Ethics in child research: children's agency and researchers' 'ethical radar'. Childhoods Today, 3(1):1-22.

Sloth-Nielsen J. 2003. Too little, too late? Provisioning for child-headed households. ESR Review, 3(1):24-25.

Smith AB. 2000. Children's rights and early childhood education: The rights of babies and young children. In: AB Smith, M Gollop, K Marshall \& K Nairn (eds). Advocating for children: International perspective on children's rights. Dunedin: University of Otago Press. 191- 205.

Smith AB. 2002. Interpreting and supporting participation rights: Contributions from sociocultural theory. International Journal of Children's Rights, 10:73-88.

Stainton Rogers W. 2004. Promoting better childhoods: Constructions of child concern. In: MJ Kehily (ed). An introduction to childhood studies. Maidenhead, England: Open University Press. 125-144. 
Stobart E. 2006. Child abuse linked to accusations of 'possession' and 'witchcraft'. Research Report No 750. United Kingdom: Department for Education and Skills.

Tangwa GB. 2011. Ethics in African Education. In: AB Nsamenang \& MS Tchombe (eds). Handbook of African Educational Theories and Practices: A Generative Teacher Education Curriculum. Cameroon: Human Development Resource Centre. 91-108.

Verhellen E. 1993. Children's rights and education. School Psychology International, 14(3):199-208.

Verhellen E. 1994. Convention on the Rights of the Child. Kessel-Lo, Belgium: Garant.

Viviers A \& Lombard A. 2013. The ethics of children's participation: Fundamental to children's rights realization in Africa. International Social Work, 56(1):7-21. 